\title{
Cholestasis Detection Enzyme Tests, in Pregnant Women with Different Hospitalization Diagnosis
}

\author{
Entela Treska $^{1,}$, , Alma Koci \\ ${ }^{1}$ University Hospital of Obstetrics and Gynaecology "Queen Geraldine”, Tirana, Albania \\ ${ }^{2}$ Clinical and Biochemical Laboratory, Health Centre nr 2, Tirana, Albania
}

\section{Email address:}

entelat@hotmail.com (E. Treska),almadaja@live.com (A. Koci)

\section{To cite this article:}

Entela Treska, Alma Koci. Cholestasis Detection Enzyme Tests, in Pregnant Women with Different Hospitalization Diagnosis. International Journal of Science and Qualitative Analysis. Vol. 1, No. 1, 2015, pp. 1-5. doi: 10.11648/j.ijsqa.20150101.11

\begin{abstract}
The aim of the study is the evaluation of serum Alkaline Phosphatase and Gamma-glutamyl Transferase levels in pregnant women as indicators of cholestasis. Cholestasis is defined as a decrease in bile flow due to the obstruction of it through intra/extra hepatic bile ducts. GGT enzyme was previously thought to be helpful in confirming a hepatic source of ALP however, GGT elevations lack the necessary specificity to be a useful confirmatory test for ALP. We analyzed 500 cases of pregnant women from year 2011-2013. Serum enzyme levels (ALP and GGT) were measured respectively using Beckman Synchron LX 20 and Enzymatic method Activity Colorimetric Kit, at the Medical Laboratory "PhD. Stelijan Buzo" in Tirana. According to the laboratory reference values of ALP (100-290 U/L): 50\% of the cases resulted normally pregnant women, 50\% suffering from liver disease $(<100 \mathrm{U} / \mathrm{L}$ or $>290 \mathrm{U} / \mathrm{L})$; whereas according to values of GGT $(8-31 \mathrm{U} / \mathrm{L})$ : $75 \%$ resulted normally pregnant women, $25 \%$ with liver damage $(<8 \mathrm{U} / \mathrm{L}$ or $>31 \mathrm{U} / \mathrm{L})$. Micronutrients deficiency leads to irreversible disorders of development; Nutritional advice would have been more effective either for the mother and the future of her child. There are few reported cases of young mothers, with sufficient income, which limit some foods due to fear of increasing body weight, while forgetting that the lack of appropriate micro-nutrients, directly affects the health of growing babies.
\end{abstract}

Keywords: Cholestasis, ALP Assay Protocol, GGT Assay Protocol, Cholestatic Enzymes, Enzymes and Pregnancy

\section{Aim of the Study}

- Evaluation and interpretation of liver enzymes such as Alkaline Phosphatase (ALP) and Glutamate-Pyruvate Transaminase (GPT) in pregnant women, with different hospitalization diagnosis, from first to third trimester of pregnancy.

- Comparison of enzyme levels in high risk pregnant women, to a control group (normal pregnant women).

- Detection of cases with liver diseases and micronutrient deficiencies.

- Identification of serious problems and various reasons of results varied from normal laboratory ranges.

\section{Introduction}

The primary importance of ALP and GGT is to serve as an indicator of cholestasis. Cholestasis includes damage to the bile flow, which can be caused by biliary tract blockages inside or outside the liver. In a normal system, bile flows from the liver into the duodenum, and it makes the body free of toxins or other major compositions, but if the area is blocked cholestasis happens [1].

\subsection{Alkaline Phophatase (ALP)}

ALP is a hydrolase enzyme responsible for removing phosphate groups from many types of molecules, including nucleotides, proteins, and alkaloids. The process of removing the phosphate group is called dephosphorylation. As the name suggests, alkaline phosphatases are most effective in an alkaline environment. It is sometimes used synonymously as basic phosphatase [2].

\subsection{Gamma-Glutamyl Transferase (GGT)}

GGT is an enzyme that transfers gamma-glutamyl functional groups. It is found in many tissues, the most notable one being the liver, and has significance in medicine as a diagnostic marker. GGT [3] catalyzes the transfer of the gamma-glutamyl moiety of glutathione to an acceptor that may be an amino acid, a peptide or water (forming glutamate). GGT plays a key role in the gamma-glutamyl cycle, a pathway for the synthesis and degradation of 
glutathione and drug and xenobiotic detoxification. Other lines of evidence indicate that GGT can also exert a prooxidant role, with regulatory effects at various levels in cellular signal transduction and cellular pathophysiology.

\section{The Study of Pregnant Women}

\subsection{Steps Taken During Work}

- Selection of cases of pregnant women at the University Hospital Of Obstetrics and Gynecology "Queen Geraldine", in Tirana, Albania.

- Study of the clinical cartels of each pregnant woman.

- Division of pregnant women in groups according to age, hospitalization diagnosis, number of deliveries, phetus age etc.

- Colection of blood samples using special test tubes (Containing EDTA or gel test tubes)

- Separation of blood serum from sediment.

- Enzyme analysis according to the procedures and work protocols.

- Statistical data proccesing using different programs such as SPSS statistics, Descriptive Statistics and Anova Single Factor

- Interpretation of the results.

\subsection{Experimental Part}

Serum enzyme analysis of ALP and GGT were done at the:

- Centre of Molecular Diagnostics and Genetic Researches, University Hospital of Obstetrics and Gynaecology, in Tirana

- Clinical-Biochemical-Medical Laboratory "PhD. Steljan Buzo", in Tirana.

\section{Material and Methods}

We took into consideration 500 cases of pregnant women, from first to third trimester of pregnancy, from year 2011 to 2013. Serum enzymes such as ALP and GGT were analyzed using the respectively methods "Beckman Synchron LX 20" and "Enzymatic colorimetric Activity Kit " [4].

\subsection{Laboratory Procedure Manual for ALP}

\subsubsection{Summary of Test Principle and Clinical Relevance}

The LX system uses an enzymatic rate using a 2-amino-2methyl-1-propanol (AMP) buffer to measure ALP activity in serum or plasma. In the reaction, the ALP catalyzes the hydrolysis of the colorless organic phosphate ester substrate, p-Nitrophenylphosphate, to the yellow colored product $\mathrm{p}$ Nitrophenol and phosphate [6,7]. This reaction occurs at an alkaline $\mathrm{pH}$ of 10.3 . The system monitors the rate of change in absorbance at $410 \mathrm{~nm}$ over a fixed-time interval. This rate of change in absorbance is directly proportional to the ALP activity in the serum. Alkaline phosphatase measurements are used in the diagnosis and treatment of liver, bone, and parathyroid disease $[8,9]$.

\subsubsection{Specimen Collection, Storage, and Handling} Procedures; Criteria for Specimen Rejection

- Interferences: No interference from bilirubin or lipemia. Do not use hemolyzed specimens.

- Separated serum or plasma should not remain at $+15^{\circ} \mathrm{C}$ to $+30^{\circ} \mathrm{C}$ longer than 8 hours. If assays are not completed within 8 hours, serum or plasma should be stored at $+2^{\circ} \mathrm{C}$ to $+8^{\circ} \mathrm{C}$. If assays are not completed within 48 hours, or the separated sample is to be stored beyond 48 hours, samples should be frozen at $-15^{\circ} \mathrm{C}$ to $20^{\circ} \mathrm{C}$. Frozen samples should be thawed only once. Analyte deterioration may occur in samples that are repeatedly frozen and thawed.

- A minimum of $0.6 \mathrm{~mL}$ serum is needed for the MultiAnalyte Panel. E. Sample volume for individual test is 5 $\mu 1$ added to $250 \mu 1$ reagent. F. Sample is run singly as part of Multi-analyte Biochemistry Pane [10,11,12].

\subsubsection{Characteristics of the Method}

Method used: Beckman Synchron LX 20

- Quick and simple method

- Requires a minimum of sample preparation

- High precision method

- Uses a wavelength of $405 \mathrm{~nm}$

- With a detection limit of $10-250 \mu \mathrm{U}$

- The kit contains p-nitrophenol standard, to build a linear calibration curve and to validate the performance of analysis [5].

\subsubsection{Equipment and Instrumentation, Reagent Preparation}

- Instrumentation: Beckman Synchron LX20

- Materials 1. Beckman Synchron CX Micro Sample Tube (Part \#448774) 2. S/P Plastic Transfer Pipet (Cat. \#P5214-10) 3. S/P Brand Accutube Flange Caps (Cat. \#T1226-37)

- Reagent Preparation: Beckman Synchron System ALP Reagent (Part \#442670, 200 tests/cartridge or Part \#476821, 400 tests/cartridge). 1. No preparation required. 2. When stored unopened at $2-8^{\circ} \mathrm{C}$, the reagent is stable until the expiration printed on the label 3. When first opened or installed on the instrument, the reagent is stable for ten days unless the expiration date is exceeded. 4. do not freeze. 5. Caustic reagent. Avoid skin contact with reagent. Use water to wash reagent from skin $[13,14]$.

- Control Material 1. Bio-Rad Liquid Unassayed Multiqual (Cat. \#697, 699). - In use from August 24, 2002 - Thaw new bottle weekly. Mix very well, using rocker prior to use. - Thawed control is stable 7 days. Mix well prior to each use [15].

\subsubsection{Limitations of Method; Interfering Substances and Conditions}

- Hemoglobin causes lower ALP results. Do not do test if sample is hemolyzed.

- Bilirubin has no significant interference [16]

- Lipemia has no significant interference. 
- Inhibitors of alkaline phosphatase activity include: oxalates, $\mathrm{Hg}++$, excess inorganic phosphate, bile acids, some amino acids (e.g., phenylalanine), and urea $[17,18]$.

\subsection{Laboratory Procedure Manual for GGT}

\subsubsection{Product Description}

The $\gamma$-Glutamyl Transferase (GGT) Enzymatic Assay Kit is a plate-based colorimetric enzymatic assay for the determination of the $\gamma$-glutamyl transferase enzyme in serum samples. $\gamma$-glutamyl transferase (GGT) is a metabolic enzyme expressed primarily in the liver, kidneys and other organs. Organ damage, especially damage to the liver, causes the release of this enzyme into the blood [19]. Elevation of GGT levels is often an indication of liver damage and has been associated with liver injury as well as pancreatic and myocardial disorders. GGT is also a very useful tool for preclinical investigation of experimental drug formulations and GGT levels are commonly used to monitor and attenuate the toxic effects of experimental drug formulations in rodents. The kit uses a spectrophotometric, kinetic assay to detect changes in $\gamma$-glutamyl transferase levels directly from serum samples. The unique features of the kit are: - High sensitivity and low detection limit [20].

\subsubsection{Kit Contents and Storage}

The $\gamma$-Glutamyl Transferase (GGT) Enzymatic Assay Kit has the capacity for 96 determinations or testing of 42 samples in duplicate (using 12 wells for standards). The kit also contains enough material to construct two standard curves. Store the kit at $4^{\circ} \mathrm{C}$. The shelf life of the kit is 12 months when properly stored $[21,22]$. Once the GGT Reagent Mix is reconstituted the shelf life of the kit is 6 months when properly stored. For more details, see "Preparation of GGT Reagent Mix". Kit Contents Amount Storage Microtiter Plate 1 x 96-well Plate (8 wells x 12 strips) $4^{\circ} \mathrm{C}$ or room temp GGT Reagent Mix Bottle $4^{\circ} \mathrm{C}$ pNA Control $0.4 \mathrm{ml} 4^{\circ} \mathrm{C}$ pNA Dilution Buffer $2 \times 1.8 \mathrm{~mL}^{\circ}{ }^{\circ} \mathrm{C}$.

\subsubsection{Required Materials}

- Microtiter plate reader (405 nm)

- Centrifuge (to prepare serum samples)

- Deionized or distilled water

- $1.5 \mathrm{~mL}$ microfuge tubes

- Multichannel pipet or repeating pipettor (Optional)

- PBS Sensitivity (Detection Limit)

- Sample Type Detection Limit (U/L)

\subsubsection{Characteristics of GGT Enzyme Methods}

Method used: Enzymatic, colorimetric Activity Kit

- Uses a wavelength of $418 \mathrm{~nm}$

- With a detection limit $0.5 \mathrm{mIU}$.

- A quick method (requires 10 minutes for each sample)

- High reproductibility

- Requires only $10 \mu \mathrm{l}$ serum

- Convenient and simple method [7,8]

\section{Results and Discussion}

The collected data were divided according to each enzyme taken into consideration. The total number of pregnant women was 500 .

\subsection{Pregnant Women Divided According to ALP and GGT Values}

Data taken from laboratory are collected to build a table and a chart, in which high risk pregnant women are seen clearly (see table 3 and 4).

Table 1. Cases divided according to ALP values.

\begin{tabular}{llll}
\hline ALP values & Condition & Nr of cases & $\%$ \\
\hline $100-290 \mathrm{U} / 1$ & Normal values & 250 & 50 \\
$>290 \mathrm{U} / 1$ & Malnutrition, liver disease & 250 & 50 \\
\hline
\end{tabular}

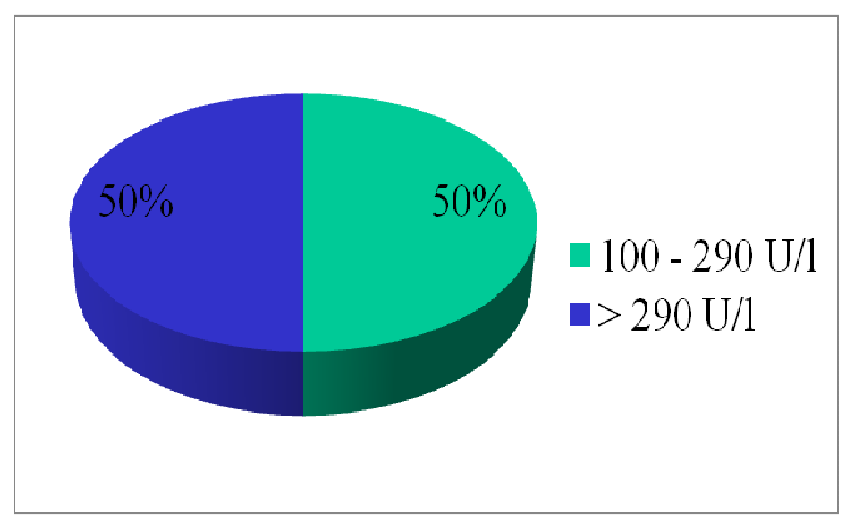

Figure 1. Values of ALP expressed in percentage.

Table 2. Cases divided according to GGT values.

\begin{tabular}{llll}
\hline GGT values & Condition & Nr of cases & $\mathbf{\%}$ \\
\hline $8-31 \mathrm{U} / 1$ & Normal values & 376 & 75 \\
$>31 \mathrm{U} / 1$ & Heart, liver damage & 124 & 25 \\
\hline
\end{tabular}

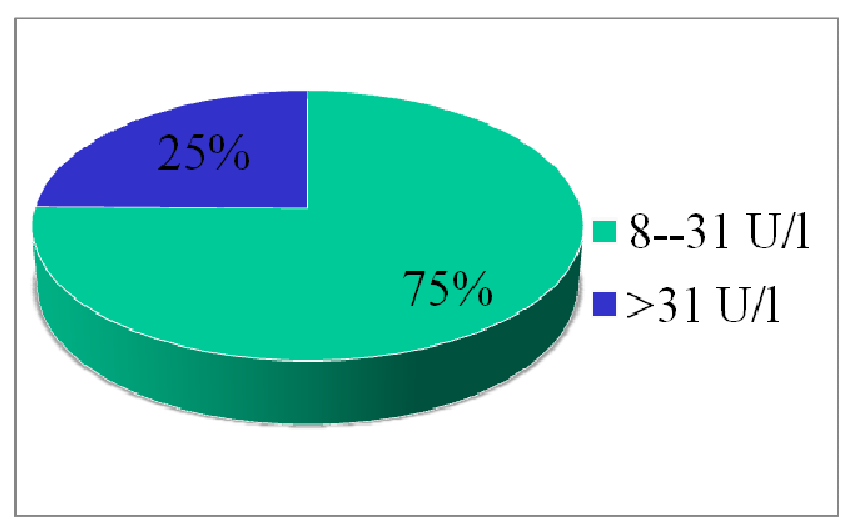

Figure 2. Values of GGT expressed in percentage.

\subsection{Pregnant Women Divided According to Diagnosis}

Pregnant women were divided according to maternal hospitalization diagnosis. The most frequent diagnosis were cephalic (138 + 18 cases) $29.6 \%$ and urinary infection (54 cases) $10.8 \%$ (table 3), whereas in cases of GGT, were cephalic $(159+10$ cases $) 33.8 \%$ and anemia $(37+24$ cases $)$ 
$12.2 \%[9]$.

Table 3. Correlation of ALP to hospitalization diagnosis.

\begin{tabular}{llllll}
\hline ALP:100-290 U/l & \multicolumn{5}{c}{ ALP > 290 U/l } \\
\hline $\begin{array}{l}\text { Hospitalization } \\
\text { Diagnosis }\end{array}$ & $\begin{array}{l}\text { Nr of } \\
\text { cases }\end{array}$ & $\%$ & $\begin{array}{l}\text { Hospitalization } \\
\text { Diagnosis }\end{array}$ & $\begin{array}{l}\text { Nr of } \\
\text { cases }\end{array}$ & $\%$ \\
\hline Abortion & 12 & 4.8 & Abortion & 24 & 9.6 \\
Anaemia & 14 & 5.6 & Anaemia & 47 & 18.8 \\
Anomalies & 14 & 5.6 & Anomalies & 19 & 7.6 \\
Cephalic & 118 & 47.2 & Cephalic & 30 & 12 \\
Twin pregnancy & 15 & 6 & Hyperemesis & 20 & 8 \\
Hyperemesis & 20 & 8 & Hypertension & 22 & 8.8 \\
Hypertension & 21 & 8.4 & Urinary infection & 54 & 21.6 \\
Partus premature & 24 & 9.6 & Partus premature & 17 & 6.8 \\
Breech delivery & 12 & 4.8 & Breech delivery & 17 & 6.8 \\
Total & 250 & 50 & Total & 250 & 50 \\
\hline
\end{tabular}

Table 4. Correlation of GGT to hospitalization diagnosis.

\begin{tabular}{llllll}
\hline GGT: 8-31 U/I & & & GGT $>31$ U/I & & \\
\hline $\begin{array}{l}\text { Hospitalization } \\
\text { Diagnosis }\end{array}$ & $\begin{array}{l}\text { Nr of } \\
\text { cases }\end{array}$ & $\%$ & $\begin{array}{l}\text { Hospitalization } \\
\text { Diagnosis }\end{array}$ & $\begin{array}{l}\text { Nr of } \\
\text { cases }\end{array}$ & $\%$ \\
\hline Abortion & 20 & 5.4 & Abortion & 15 & 12 \\
Anaemia & 37 & 9.8 & Anaemia & 24 & 19.4 \\
Anomalies & 26 & 7 & Anomalies & 10 & 8.1 \\
Cephalic & 159 & 42.3 & Cephalic & 10 & 8.1 \\
Hyperemesis & 25 & 6.6 & Hyperemesis & 12 & 9.7 \\
Hypertension & 29 & 7.7 & Hypertension & 10 & 8.1 \\
Urinary Infection & 14 & 3.7 & Urinary Infection & 11 & 8.8 \\
Partus premature & 47 & 12.5 & Partus premature & 20 & 16.1 \\
Breech delivery & 19 & 5 & Breech delivery & 12 & 9.7 \\
Total & 376 & 75 & Total & 124 & 25 \\
\hline
\end{tabular}

\section{Conclusions}

According to the normal laboratory values for ALP:

- $50 \%$ of pregnant women (250 cases) resulted normal $(100-290 \mathrm{U} / \mathrm{l})$, of which $47.2 \%$ (118 cases) were cephalic.

- $50 \%$ proved that suffered from liver disease ( $\geq 290 \mathrm{U} /$ L), of which $21.6 \%$ (54 cases) resulted with urinary infection.

According to the normal laboratory values of GGT:

- $75 \%$ resulted normal pregnant women $(8-31 \mathrm{U} / \mathrm{L})$, of which $42.3 \%$ (159 cases) were cephalic

- $25 \%$ resulted that have had liver damage ( $\geq 31 \mathrm{U} / \mathrm{L})$, of which $19.4 \%$ were with anaemia.

Micronutrient deficiencies risked leading to irreversible disorders of phetus development.

\section{Recommendations}

- Pregnant women, after becoming responsible for the above risks, must seek medical staff strict execution of protocols for the prosecution of pregnancy as well as good-nutrition during pregnancy and also during the first month after birth.

- If there are no nutritional requirements, pregnant woman will fall in nutrient deficiency.

- Nutritional advice would have been more effective for the mother and her child to be.
- ALP and GGT tests are important to be done to check bone problems and also liver damage [6].

\section{References}

[1] PDB 1ALK: Kim EE, Wyckoff HW "Reaction mechanism of alkaline phosphatase based on crystal structures. Two-metal ion catalysis". J. Mol. Biol. 218 (2): 449-64. doi:10.1016/0022-2836(91)90724-K. PMID 2010919, (March 1991).

[2] Tamás L, Huttová J, Mistrk I, Kogan G "Effect of Carboxymethyl Chitin-Glucan on the Activity of Some Hydrolytic Enzymes in Maize Plants" (PDF).Chem. Pap. 56 (5): 326-329 (2002).

[3] Tamás L, Huttová J, Mistrk I, Kogan G "Effect of Carboxymethyl Chitin-Glucan on the Activity of Some Hydrolytic Enzymes in Maize Plants". Chem. Pap. 56 (5): 326-329, (2002).

[4] Chernecky CC, Berger BJ Laboratory Tests and Diagnostic Procedures, 5th ed. St. Louis: Saunders (2008).

[5] Fischbach FT, Dunning MB III, eds. Manual of Laboratory and Diagnostic Tests, 8th ed. Philadelphia: Lippincott Williams and Wilkins (2009).

[6] Beckman Synchron LX Systems Chemistry Information Manual, 2001.

[7] Tietz, N.W. Textbook of Clinical Chemistry, W.B. Saunders, Philadelphia, PA (1986).

[8] Tietz, N.W., "Specimen Collection and Processing; Sources of Biological Variation," Textbook of Clinical Chemistry, 2nd Edition, W.B. Saunders, Philadelphia, PA (1994).

[9] National Committee for Clinical Laboratory Standards, Procedures for the Handling and Processing of Blood Specimens, Approved Guideline, NCCLS publication H18-A, Villanova, PA (1990).

[10] Tietz, N.W., ed., Clinical Guide to Laboratory Tests, 3rd Edition, W.B. Saunders, Philadelphia, PA (1995).

[11] National Committee for Clinical Laboratory Standards, How to Define, Determine, and Utilize Reference Intervals in the Clinical Laboratory, Approved Guideline, NCCLS publication C28-A, Villanova, PA (1995).

[12] Tietz, N.W., ed., Fundamentals of Clinical Chemistry, 3rd Edition, W.B. Saunders, Philadelphia, PA (1987).

[13] Henry, J.B., ed., Clinical Diagnosis and Management by Laboratory Methods, 18th Edition, W.B. Saunders, Philadelphia, PA (1991).

[14] Young, D.S., Effects of Drugs on Clinical Laboratory Tests, 4th Edition, AACC Press, Washington, D.C. (1995).

[15] Friedman, R.B. and D.S. Young, Effects of Disease on Clinical Laboratory Tests, 3rd Edition, AACC Press, Washington, D.C. (1997).

[16] Young, D.S., Effects of Preanalytical Variables on Clinical Laboratory Tests, 2nd Edition, AACC Press, Washington, D.C. (1997). 
[17] National Committee for Clinical Laboratory Standards, Method Comparison and Bias Estimation Using Patient Samples; Approved Guideline, NCCLS publication EP9-A, Villanova, PA (1995).

[18] National Committee for Clinical Laboratory Standards, Precision Performance of Clinical Chemistry Devices, Tentative Guideline, 2nd Edition, NCCLS publication EP5-T2, Villanova, PA (1992).

[19] Tate SS, Meister A "gamma-Glutamyl transpeptidase from kidney".Methods in Enzymology 113: 400-419. doi:10.1016/S0076-6879(85)13053-3.ISBN 978-0-12-1820138. PMID 2868390, (1985).
[20] Courtay C, Oster T, Michelet F, Visvikis A, Diederich M, Wellman $\mathrm{M}$ et al. "Gamma-glutamyltransferase: nucleotide sequence of the human pancreatic cDNA. Evidence for a ubiquitous gamma-glutamyltransferase polypeptide in human tissues". Biochemical Pharmacology 43 (12): 2527-2533. doi:10.1016/0006-2952(92)90140-E. PMID 1378736, (Jun 1992).

[21] Vázquez-Medina, J. P., et al. (April 2011) Prolonged fasting increases glutathione biosynthesis in post weaned northern elephant seals. J. Exp. Biol., 214: 1294 - 1299

[22] Tate SS, Meister A "gamma-Glutamyl transpeptidase from kidney". Meth. Enzymol. Methods in Enzymology 113: 400419. ISBN 978-0-12-182013-8, (1985). 